\title{
Perceived Psychiatric Nurses Job Stress: A cross sectional study
}

\author{
Eman Dawood $^{1,2^{*}}$, Rufa Mitsu ${ }^{2} \&$ Agnes Monica ${ }^{2}$ \\ ${ }^{1}$ Psychiatric Mental Health Nursing Department, College of Nursing, Menofyia University, Shebin El - Kom, \\ Egypt. \\ ${ }^{2}$ Psychiatric and Mental Health Nursing, College of Nursing, King Saud bin Abdulaziz University for Health \\ Sciences, Riyadh, Kingdom of Saudi Arabia.
}

\begin{abstract}
The dispute of job stress among nurses is one of the core concerns in the field of psychiatric nursing, it was found that stress brought harmful impacts on both nurses' health and their ability to cope with job demands. The aim of this study was to examine the level of job stress among registered psychiatric nurses working in different psychiatric units of a major governmental psychiatric hospital located at the central region of the Kingdom of Saudi Arabia. A descriptive correlation cross section research design was utilized on a convenience sample of 137 psychiatric nurses. The data collection instruments used were a demographic data sheet and Psychiatric Nurse Job Stress Scale by Yada, Abe, Funakoshi, Omori, Matsuo, Ishida \& Katoh (2011). Participants were given information regarding the purpose and nature of the study. Subjects were assured about the confidentiality and anonymity of all collected data. Data were analyzed using SPSS version 22.0. The psychiatric nurse job stress scale total score ranged between 16 and 88 with a mean score of $47.95 \pm 10.09$, indicating that half of the psychiatric nurses included in the study had moderate level of job stress. Furthermore Pearson $R$ revealed strong statistical correlations between total PNJSS total score and all its four subscales. The study results, revealed that most psychiatric nurses were experiencing moderate level of job stress. Continuous workshop for understanding the unique stressors that have an impact on psychiatric nurses will help to increase the stress bearing capacity among nurses working in different psychiatric and mental health clinical areas.
\end{abstract}

Key words: job stress, psychiatric nursing, work place, psychological stress, burnout

\section{Introduction}

Psychiatric nurses are professionals who assist people regain a sense of coherence over what is occurring to them, be it a result of trauma or some other form of mental distress. Their unique contribution has been in the simple elegance of 'being there' to bear witness and mitigate the negative side effects of illnessalienation and a feeling of being out of touch with the self and social context (Stuhlmiller, 2003). Job stress is defined as the stress connected with professional or work environment, a pressure that overrun when the burdens of the job go beyond the capability of an individual to react efficiently (Mcvicar, 2003).The dispute of job stress among nurses is one of the core concerns in psychiatric nursing. According to the national institute for occupational safety health, nursing was found to be one of jobs that had boundless than anticipated level of stress, it was found that stress brought harmful impacts on both nurses health and their ability to cope with job demands (Adriaenssens, 2013)

Even though many of the job stress confronted by psychiatric nurses are similar to those stated by staff in other nursing specialties, a number of difficulties relate explicitly to mental health settings. Psychiatric nursing is being considered as a stressful specialty, with low job satisfaction. Long term exposure to job-related stress can lead to burn out and reduce their level of satisfaction. Psychiatric nurses are important members of the multi-disciplinary team who caters to the needs of psychiatric patients in a therapeutic environment (Konstantinos \& Christina, 2016).

In most psychiatric hospitals, nurses have to work in a highly stressful environment where they face stressors like shortage of nurses, unpredictable patient behavior like aggression and violence in the unit. Psychiatric nurses face with variety of stressors in the work environment. Most employees of mental health settings encounter situations in their careers that are uncomfortable or distressing. Each individual responds in a slightly different manner to each presented situation in general and the discomfort level of each individual differ in a given situation. A variety of factors might influence a professional's response to stressful situations including past work experiences, professional training, and each individual's personality style (Duquette, Kerouac \& Sandhu, 1994). Thus, the work exposure to stressful situations can lead to depression, violent behavior and other diseases in psychiatric nurses (Robinson, Clements \& Land, 2003).

However, developing the skills to interact appropriately in the work setting can be challenging. In a mental health setting, appropriate interactions between nurses and their patients, coworkers, and supervisors are important for improved quality of services. In fact, many educational programs for health care professionals do not provide extensive training and preparation regarding interpersonal interactions in the work environment. 
(Palmer, Boykin, Lythgoe, Bizzell \& Daiss, 2005). Although the past decades witnessed significant landmarks in capacity building in nursing education and services, as well as in the improvement of nurses' image and status, many issues remain same, especially those who work in government psychiatric hospitals (Alsaraireh, Quinn, Griffin, Ziehm \&Fitzpatrick, 2014).

The fact that psychiatric nurses get less affirmation from their role raises difficulties for nurses in this specialty to give each other positive feedback for their work. In addition, it was found that psychiatric nurses received less aid or direct assistance from colleagues than other specialties, emphasizing that interdependence is not required by the psychiatric team work. It is evident that interpersonal relationships were the most frequent sources of undesirable personal stress for psychiatric nurses and that it had a greater impact on them than on nurses of other specialties. A comparative study of psychiatric nurses and nurses working in operation theatres, intensive care and general medicine, among 269 female nurses found that psychiatric nurses experienced intense interpersonal involvement and stated that frequent conflicts took place in their working environment with patients, families, physicians and colleagues (Cronin Stubbs and Brophy, 1985).

The roles of nurses have continued to expand over the years, in association with increase in the mental health services provided by psychiatric departments. Therefore, improving mental health care and working conditions for psychiatric nurses is an important issue (Fioritti, Giaccotto \& Melega, 1997). To identify sources of job stress specifically in psychiatric nurses, a telephone survey among 43 psychiatric nurses was conducted in a large psychiatric hospital that explored negative patient characteristics which accounts for $9 \%$ of stressors and physical threats from patients and staff conflicts accounts for $21 \%$ of the stressors. The highest stressors were working with poorly motivated staff and having a doctor who fails to notify staff about changes in patient's order and also convincing doctors to order adequate medication (Dawkins, Depp \& Selzer, 1985). Job stress and burnout in 78 psychiatric nurses working in eight acute admission wards in the UK found that violence, potential suicide and observation are the most frequent stressors in patient care. The intensity of stressful circumstances experienced by psychiatric nurses were due to lack of manpower to maintain observations at a safe level, psychiatric nurses lack of understanding and support from hospital management and the type of patient care the psychiatric nurses provide possibly would be the major cause of job stress (Sullivan, 1993).

In Saudi Arabia, researchers identified a positive relationship between years of experience, organizational commitment, and job satisfaction as well as age and years of work experience are related variables, as younger nurses who have less work experience are more dissatisfied with their accomplishments, professional support and workload (Al-Ahmadi, 2009). According to Wang, Kong \& Chair (2011) the relationship between job satisfaction, occupational commitment, and intent to stay suggests that personal characteristics have important influences on nurses' job satisfaction and turnover intention. Moreover it was recognized that individuals might view their work life differently in relation to other aspects of their personal and professional lives.

It is noteworthy to note that male and female psychiatric nurses have dissimilarity in job stress, female nurses had significantly greater levels of stress than male nurses in the areas of psychiatric nursing care ability, attitude towards nursing, fatigue, and anxiety (Olivia, 2011), while male nurses, had higher irritability towards attitude of patients (Yada, Abe \& Omori, 2014). The difference between male and female psychiatric nurses' job performance and job satisfaction levels on an acute care inpatient unit explored the concepts from social role theory that gender identity and expectations influence job performance in psychiatric nursing (Torkelson \& Seed, 2011).

Psychiatric nurses, especially the young ones who haven't developed defensive mechanisms feel frustrated when their attempt to improve patients' quality of life are unsuccessful. Handy (1990) in an in-depth case study examined job stress among psychiatric nurses in England from a different perspective. Qualitative techniques were used to collect data from nurses working in two different wards within a large psychiatric hospital and a community psychiatric nursing unit attached to the same hospital. It was found that stress in psychiatric nurses occurred due to the contradictory therapeutic role which is attributed to the concept of psychiatric care and control-oriented practice which is used to organize daily activities. However, nurses failed to understand that in order to increase their understanding, particularly about job stress they need to consider the factors affecting the organization as well as the social context of psychiatric wards. Thus, the study concluded that psychiatric nurses in an effort to recreate a system in the ward lead to job stress and dissatisfaction.

Likewise, nurses were found to be dissatisfied with their work, they expressed some issues like lack of autonomy, undervalue by the medical staff and nurse managers, lack of opportunities for professional development, lack of support from managers for professional development, lack of recognition and low morale (Callaghan,1991). Nurse's level of job satisfaction assessed on 22 psychiatric nurses working in a psychiatric unit attached in a general hospital in Australia revealed that there was a feeling of lack of teamwork between peers as well as amongst the multidisciplinary team of the unit (Farrel \& Dares, 1999). Lack of adequate staffing levels of support at work, family and friends, emotional exhaustion, depersonalization and lack of personal accomplishment are frequently cited indicators of job stress in mental health settings (Kilfedder Catherine, 
Kevin \&Tony, 2001). Studies on job stress in psychiatric nursing have been slower to emerge. Although much research had focused on job stress among psychiatric nurses, to the best of the investigators knowledge, only few studies investigating the job-related stress have been conducted among nurses working in psychiatric hospitals at Kingdom of Saudi Arabia. In light of the above concerns, the present study therefore aimed to assess the level of job stress among registered psychiatric nurses working in different psychiatric units of a major governmental psychiatric hospital located at the central region of the Kingdom of Saudi Arabia.

The aim of this study was to examine the level of job stress among registered psychiatric nurses working in different psychiatric units of a major governmental psychiatric hospital located at the central region of the Kingdom of Saudi Arabia.

\subsection{Research Questions}

\section{Subjects and Methods}

1. What is the level of job stress among registered psychiatric nurses?

2. What is the difference in level of job stress among male and female registered psychiatric nurses?

3. What is the difference in level of job stress among Saudi and other nationality registered psychiatric nurses?

4. Is there a relationship between Gender, work place, degree of education, years of experience and job stress level among registered psychiatric nurses?

\subsection{Research Design}

This study used a descriptive - correlation cross section research design to examine the level of job stress among registered psychiatric nurses working in different psychiatric units of a major governmental psychiatric hospitals.

\subsection{Setting}

The study was conducted in a major governmental psychiatric hospital located at the central region of the Kingdom of Saudi Arabia.

2.4 Sample

The participants for this study were individuals who work as a psychiatric nurse in different psychiatric units at a major governmental psychiatric hospital located at the central region of the Kingdom of Saudi Arabia. The researcher utilized a non-probability convenience sample of 137 nurses who voluntarily agreed to participate in the study.

\subsection{Tools and Measurements of Data collection}

The data collection instruments used to operationalize the variables in this study were a demographic data questionnaire designed by the researcher to collect specific information pertaining to the participants and The Psychiatric Nurse Job Stress Scale by Yada, Abe, Funakoshi, Omori, Matsuo, Ishida \& Katoh (2011) which is a 5 point Likert scale with 22 items, of which 9 statements are positive and remaining 13 statements are negative, negative statements scoring was reversed. Each statement was scored with $0=$ Never; $1=$ Rarely; $2=$ Sometime; $3=$ Often; $4=$ Always, that assesses the job stress related to psychiatric nursing ability (9 items), attitude of patients (6 items), attitude toward nursing (5 items) and communication ( 2 items). The highest possible score of PNJSS is 88 indicating higher Job stress, with psychiatric nursing ability subscale score range of $0-36$ that measures feelings of lack of nursing ability due to job stress, attitude of patients subscale score of $0-24$, this subscale measures negative emotions from patients, attitude toward nursing, subscale score range of $0-20$ that measures the perceived incongruity between the respondents' attitudes and the attitudes of other staff and communication, subscale score of $0-4$ that measures difficulty in communicating with patients and their families. The Cronbach's alpha coefficient was 0.816 for the scale and ranged between 0.675 and 0.869 for each subscale. The test-retest reliability coefficient was $0.717(\mathrm{P}<0.01)$ for the scale which is a strong level. With regard to scale validity, the convergent validity of the job stress scale is $r=0.172-0.420$ ( $P<0.01)$, and the predictive validity of the Job stress scale is $r=0.201-0.453$ (P $<0.01$ ). Pilot study was conducted to test the feasibility and applicability of the tool. Pilot study was carried out on ten subjects who were excluded from the study and the result of the pilot study helped in refining the translation of some questions.

\subsection{Ethical Consideration}

An informed consent was granted from each participant after explanation of the purpose and nature of the current study. Involvement in this study was strictly voluntary. All of the participants had the absolute right to withdraw from the study for whatever reason up until the point at which the questionnaires were returned to the researcher. In addition to the participant's informed consent, they were also guaranteed confidentiality and anonymity. No identifying information were collected and all participants were assured that all collected data will be confidential and will be used only for the research purposes. 


\subsection{Data Collection}

Unit managers supervising the psychiatric units in the aforementioned hospital were contacted to request permission to conduct this research at their respective facilities. Each participant was provided with a consent form. The researchers scheduled appointments and subsequently gave a brief, oral presentation to the nurses who were present at each location and each participant received the survey questionnaires at convenience. All of the participants were instructed to return the research information to the unit manager upon completion. The data were collected over a three months period from December 2015 until February 2016.

\subsection{Data Analysis}

The Statistical Package of the Social Scientists (SPSS) Version 22.0 was utilized to analyze the quantitative data. Once the surveys were received from the participants, the data were immediately coded and entered into SPSS. Descriptive statistics were utilized to describe the sample characteristics and to evaluate whether the results were normally distributed. Pearson's correlation coefficients were used to determine the strength and direction of relationships among variables. Appropriate statistical methods were utilized to compare between the groups. The significance level was chosen as $(\mathrm{p}<0.05)$.

\section{Results}

As presented in table 1, total number of the nurses included in the study was 137 nurses from all departments in the mental health hospital. Male participants constituted $59.1 \%$ while $40.9 \%$ of the participants were females. Age of the participants ranged between 20 to 55 years with a mean age of $31.01 \pm 7.53$ Years. Years of experience as a psychiatric nurse ranged between one month and 22 years with a mean experience of $56.72 \pm 61.03$ months. Only three participants held a master degree in nursing while $32.1 \%$ held a bachelor degree in nursing and around two thirds of the participants $(65.7 \%)$ held a diploma degree in nursing. More than half of the participants $(61.3 \%)$ were Saudi while the rest were non Saudi recruited from other countries including Jordon, Egypt, India, Philippine, Indonesia and Sudan. 83.9\% of the participants had Arabic language as their mother tongue language which is at the same time the official language for all Saudi citizens.

Table 1: Characteristics of the participants $(n=137)$

\begin{tabular}{|l|r|r|}
\hline \multicolumn{1}{|c|}{ Variable } & Frequency & Percentage \\
\hline Gender & & 59.1 \\
Male & 56 & 40.9 \\
Female & & \\
\hline Marital Status & 59 & 43.1 \\
Single & 78 & 56.9 \\
Married & & \\
\hline Level of Education & 90 & 65.7 \\
Diploma & 44 & 32.1 \\
Bachelor & 3 & 2.2 \\
Master & & \\
\hline Nationality & 84 & 61.3 \\
Saudi & 53 & 38.7 \\
Non Saudi & 23 & 43.4 \\
Jordanian & 5 & 9.4 \\
Egyptian & 19 & 35.8 \\
Indian & 2 & 3.8 \\
Indonesia & 2 & 3.8 \\
Pilipino & 1 & 1.9 \\
French & 1 & 1.9 \\
Sudan & & \\
\hline Mother Tongue & 115 & 83.9 \\
Arabic & 22 & 16.1 \\
Non Arabic & & \\
\hline Place of Work & 44 & 32.1 \\
Acute Care Unit & 25 & 18.2 \\
Chronic Care Unit & 14 & 7.3 \\
Emergency Department & 10 & 29.2 \\
Outpatient Clinic Department & 40 & 2.9 \\
Addiction Unit & 4 & \\
Occupational Therapy Unit & & 5 \\
\hline & & \\
\hline
\end{tabular}

Table 2 presents the participants responses to psychiatric nurse job stressor scale, the most highly ranked statements were I think that I can nurse and correspond as the case requires $(2.97 \pm 0.97)$, I think that I can explain the nursing that I am doing $(2.92 \pm 0.98)$, I think that I have psychiatric nursing ability $(2.89 \pm$ 
0.96), I think that I have knowledge about the laws, the institutions and the policies necessary for nursing $(2.87$ $\pm 0.92)$, I think that I can express my opinion in front of others $(2.74 \pm 1.03)$ and I feel that I can do integrated nursing $(2.78 \pm 0.89)$. The least reported statements were I feel that there are patients who have an unpleasant attitude toward me $(1.28 \pm 1.20)$, I feel that patients are negative about me $(1.32 \pm 1.17)$ and I feel that there are patients who are threatening and make me afraid $(1.36 \pm 1.09)$

Table 2: Participants Responses to Psychiatric Nurse Job Stressor Scale ( $\mathrm{n}=137)$

\begin{tabular}{|c|c|c|c|c|c|c|}
\hline Statement & $\begin{array}{l}\text { Never } \\
\text { N }(\%)\end{array}$ & $\begin{array}{l}\text { Rarely } \\
\text { N }(\%)\end{array}$ & $\begin{array}{l}\text { Sometime } \\
\mathbf{N}(\%)\end{array}$ & $\begin{array}{r}\text { Often } \\
\text { N }(\%)\end{array}$ & $\begin{array}{l}\text { Always } \\
\mathbf{N}(\%)\end{array}$ & $\mathbf{M} \pm \mathbf{S D}$ \\
\hline \multicolumn{7}{|l|}{ Psychiatric Nursing Ability (9 Items) } \\
\hline $\begin{array}{l}\text { 1. I think that I can nurse and correspond as the } \\
\text { case requires }\end{array}$ & $3(2.2)$ & $4(2.9)$ & $37(27)$ & $43(31.4)$ & $50(36.5)$ & $2.97 \pm 0.97$ \\
\hline $\begin{array}{l}\text { 2. I think that I can explain the nursing that I } \\
\text { am doing }\end{array}$ & $2(1.5)$ & $9(6.6)$ & $31(22.6)$ & $48(35)$ & $47(34.3)$ & $2.92 \pm 0.98$ \\
\hline 3. I think that I have psychiatric nursing ability & $2(1.5)$ & $9(6.6)$ & $33(24.1)$ & $54(39.4)$ & $39(28.5)$ & $2.89 \pm 0.96$ \\
\hline $\begin{array}{l}\text { 4. I think that my experience has been made } \\
\text { use of on the job }\end{array}$ & $7(5.1)$ & $11(8)$ & $33(24.1)$ & $50(36.5)$ & $36(26.3)$ & $2.68 \pm 1.13$ \\
\hline 5. I feel that my role as a nurse is well-defined & $11(8)$ & $9(6.6)$ & $40(29.2)$ & $36(26.3)$ & $41(2939)$ & $2.64 \pm 1.20$ \\
\hline 6. I think that I understand the patients & $2(1.5)$ & $8(5.8)$ & $61(44.5)$ & $35(25.5)$ & $31(226)$ & $2.63 \pm 1.00$ \\
\hline $\begin{array}{l}\text { 7. I think that I can express my opinion in front } \\
\text { of others }\end{array}$ & $2(1.5)$ & $11(8)$ & $49(35.8)$ & $34(24.8)$ & $41(29.9)$ & $2.74 \pm 1.03$ \\
\hline $\begin{array}{l}\text { 8. I think that I have knowledge about the laws, } \\
\text { the institutions and the policies necessary for } \\
\text { nursing }\end{array}$ & $1(0.7)$ & $12(8.8)$ & $33(24.1)$ & $54(39.4)$ & $37(27)$ & $2.87 \pm 0.92$ \\
\hline $\begin{array}{l}\text { 9. I feel that the direction my nursing is } \\
\text { advancing in is not clearly defined }\end{array}$ & $10(7.3)$ & $26(19)$ & $46(33.6)$ & $26(19)$ & $29(21.2)$ & $1.75 \pm 1.20$ \\
\hline \multicolumn{7}{|l|}{ Attitude of Patients (6 items) } \\
\hline 10. I feel that patients are negative about me & $7(5.1)$ & $12(8.8)$ & $43(31.4)$ & $28(20.4)$ & $47(34.3)$ & $1.32+1.17$ \\
\hline $\begin{array}{l}\text { 11. I feel that there are patients who have an } \\
\text { unpleasant attitude toward me }\end{array}$ & $7(5.1)$ & $13(9.5)$ & $29(21.2)$ & $44(32.1)$ & $44(32.1)$ & $1.28 \pm 1.20$ \\
\hline $\begin{array}{l}\text { 12. I feel that there are patients who are } \\
\text { threatening and make me afraid }\end{array}$ & $8(5.8)$ & $8(5.8)$ & $39(28.5)$ & $48(35)$ & $34(24.8)$ & $1.36 \pm 1.09$ \\
\hline $\begin{array}{l}\text { 13. I feel that I might get entangled in patients' } \\
\text { behavior }\end{array}$ & $10(7.3)$ & $16(11.7)$ & $44(32.1)$ & $37(27)$ & $30(21.9)$ & $1.54 \pm 1.13$ \\
\hline $\begin{array}{ll}14 . & \text { I feel that I am pressured by patients' } \\
\text { demands }\end{array}$ & $13(9.5)$ & $19(13.9)$ & $61(44.5)$ & $27(19.7)$ & $17(12.4)$ & $1.87 \pm 1.07$ \\
\hline $\begin{array}{l}\text { 15. I feel that patients make impossible } \\
\text { demands on me }\end{array}$ & $14(10.2)$ & $23(16.8)$ & $40(29.2)$ & $37(27)$ & $23(16.8)$ & $1.78 \pm 1.17$ \\
\hline \multicolumn{7}{|l|}{ Attitude toward Nursing (5 items) } \\
\hline $\begin{array}{l}\text { 16. I feel that there is a difference between the } \\
\text { philosophy of the institution and the reality }\end{array}$ & $33(24.1)$ & $24(17.5)$ & $49(35.8)$ & $24(17.5)$ & $7(5.1)$ & $2.35 \pm 1.15$ \\
\hline $\begin{array}{l}\text { 17. I feel that there is the gap between my ideal } \\
\text { and actual nursing }\end{array}$ & $25(18.2)$ & $29(21.2)$ & $62(45.3)$ & $16(11.7)$ & $5(3.6)$ & $2.35 \pm 1.00$ \\
\hline $\begin{array}{l}\text { 18. I feel that there is difference among nurses } \\
\text { in the way of thinking about of nursing }\end{array}$ & $14(10.2)$ & $24(17.5)$ & $66(48.2)$ & $27(19.7)$ & $6(4.4)$ & $2.08 \pm 0.96$ \\
\hline $\begin{array}{l}\text { 19. I feel that I have a difference of opinion } \\
\text { with my superior }\end{array}$ & $8(5.8)$ & $15(10.9)$ & $49(35.8)$ & $34(24.8)$ & $31(22.6)$ & $1.59 \pm 1.13$ \\
\hline 20. I feel that I can do integrated nursing & $2(1.5)$ & $9(6.6)$ & $46(33.6)$ & $46(33.6)$ & $34(24.8)$ & $2.78 \pm 0.89$ \\
\hline \multicolumn{7}{|l|}{ Communication (2 items) } \\
\hline $\begin{array}{l}\text { 21. I think it is difficult to communicate with } \\
\text { the family of patients }\end{array}$ & $6(4.4)$ & $27(19.7)$ & $60(43.8)$ & $23(16.8)$ & $21(15.3)$ & $1.91 \pm 1.04$ \\
\hline $\begin{array}{l}\text { 22. I think it is difficult to communicate with } \\
\text { patients }\end{array}$ & $7(5.1)$ & $12(8.8)$ & $58(42.3)$ & $43(31.4)$ & $17(12.4)$ & $1.67 \pm 0.98$ \\
\hline
\end{tabular}

The possible total psychiatric nurse job stressor scale score range between $0-88$ with psychiatric nursing ability subscale score range of $0-36$ that measures feelings of lack of nursing ability due to job stress, attitude of patients subscale score of $0-24$, this subscale measures negative emotions from patients, attitude toward nursing subscale score range of $0-20$ that measures the perceived incongruity between the respondents' attitudes and the attitudes of other staff and communication subscale score of $0-4$ that measures difficulty in communicating with patients and their families. In the current study, total psychiatric nurse job stressor scale total score ranged between 16 and 88 with a mean score of $47.95 \pm 10.09$. Psychiatric nursing ability subscale total score ranged between 2 and 36 with a mean subscale score of 24.09 and standard deviation of 5.66, minimum score of attitude of patients subscale was 0 and maximum score was 24 with mean score of $9.14 \pm$ 5.26, attitude toward nursing subscale score ranged between 3 and 20 with a mean subscale score of $11.14 \pm$ 2.98 , and communication subscale score ranged between 0 and 8 with a mean score of $3.58 \pm 1.79$.

To categorize the participants according to the level of perceived stress, those participants who scored 0-22 in the PNJSS were referred to as having low level of job stress, 23-44 mild job stress, 45-66 moderate job stress 
and 67 and above were experiencing severe job stress. Data analysis showed that more than half of the participants in this study experienced moderate levels of job stress $(\mathrm{N}=83,60.6 \%)$, more than a third of the participants $(n=47,34.3 \%)$ perceived mild levels of job stress while only six participants $(4.4 \%)$ perceived severe psychiatric nursing job stress.

Graph 1: Distribution of the Participants According to the Level of Perceived Job Stress ( $\mathrm{n}=137$ )

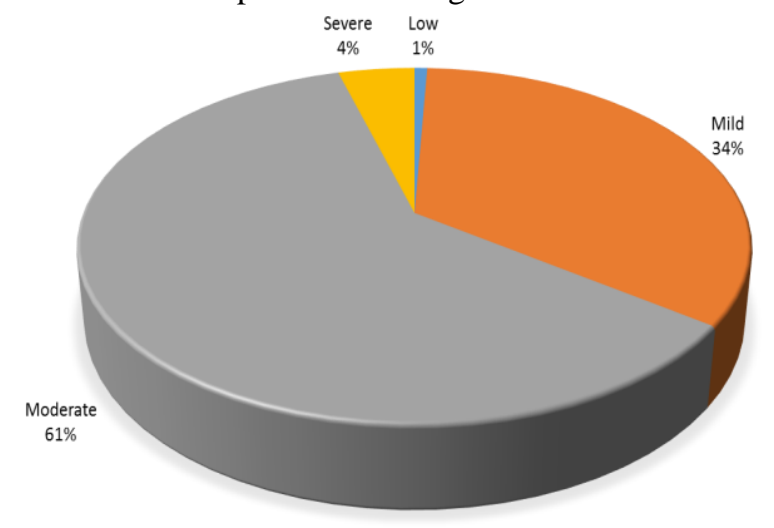

Table 3 represent the differences between male and female nurses in relation to psychiatric nurse job stressor scale total score and its four subscale scores. Results of the data analysis revealed only significant differences between male and female participants in relation to total PNJSS mean scores and the communication subscale mean score $(\mathrm{p}=0.016,0.000)$.

Table 3 Comparison of the Total Scores of the Psychiatric Nurse Job Stressor Scale (PNJSS) and Its Subscales between Male and Female Nurses ( $\mathrm{n}=137)$

\begin{tabular}{|l|r|r|r|r|}
\hline PNJSS Categories and Subscales & \multicolumn{1}{|c|}{ Male $(\mathbf{n}=\mathbf{8 5})$} & Female $(\mathbf{n}=\mathbf{5 3})$ & t & P \\
\hline Psychiatric nursing ability subscale & $24.40 \pm 4.95$ & $23.62 \pm 6.61$ & 0.787 & 0.433 \\
\hline Attitude of patients subscale & $9.86 \pm 4.78$ & $8.00 \pm 5.76$ & 2.051 & 0.042 \\
\hline Attitude toward nursing subscale & $11.19 \pm 2.84$ & $11.08 \pm 3.18$ & 0.216 & 0.829 \\
\hline Communication subscale & $4.14 \pm 1.56$ & $2.68 \pm 1.77$ & 5.079 & 0.000 \\
\hline Total PNJSS & $49.59 \pm 9.12$ & $45.38 \pm 11.0$ & 2.435 & 0.016 \\
\hline
\end{tabular}

As presented in table 4 independent samples $t$ test revealed statistically significant differences between Saudi and non-Saudi nurses working in psychiatric settings with regard to mean scores of the psychiatric nursing ability subscale $(\mathrm{p}=0.000)$, attitude of patients subscale $(\mathrm{p}=0.002)$, attitude toward nursing subscale ( $\mathrm{p}$ $=0.02)$ and the communication subscale $(\mathrm{p}=0.05)$, while nationality made no difference in the mean total score of the PNJSS. Marital status in terms of being single or married had no effect on the participants' mean total scores of the PNJSS or any of the means of its subscales as revealed by $t$ test for independent samples. Having Arabic language as the mother tongue language was negatively associated with the psychiatric nursing ability subscale $(t=-4.049, p=0.000)$ indicating low levels of psychiatric nurse job stress and was associated with communication subscale $(t=3.674, p=0.001)$ indicating less difficulty in communicating with patients and their families.

Table 4 Comparison of the Total Scores of the Psychiatric Nurse Job Stressor Scale (PNJSS) and Its Subscales between Saudi and Non Saudi Nurses $(n=137)$

\begin{tabular}{|l|r|r|r|l|}
\hline PNJSS Categories and Subscales & Saudi $(\mathbf{n}=\mathbf{8 4})$ & Non Saudi $(\mathbf{n}=\mathbf{5 3})$ & \multicolumn{1}{|c|}{ t } & \multicolumn{1}{|c|}{ P } \\
\hline Psychiatric nursing ability subscale & $22.46 \pm 5.83$ & $26.65 \pm 4.24$ & 4.87 & 0.000 \\
\hline Attitude of patients subscale & $10.19 \pm 5.51$ & $7.52 \pm 4.36$ & 3.165 & 0.002 \\
\hline Attitude toward nursing subscale & $11.57 \pm 3.19$ & $10.48 \pm 2.46$ & 2.265 & 0.026 \\
\hline Communication subscale & $3.81 \pm 1.84$ & $3.22 \pm 1.66$ & 1.946 & 0.054 \\
\hline Total PNJSS & $48.04 \pm 11.98$ & $47.87 \pm 6.07$ & 0.107 & 0.915 \\
\hline
\end{tabular}

Table 5 presents the correlation between age and length of experience in months with the psychiatric nurse job stressor scale total score and its four subscale scores. Only statistically significant correlation was found between length of experience as a psychiatric nurse and the communication subscale $(p=0.01)$. Age had no correlation with any of the PNJSS total scale score or any of its categories. 
Table 5 Correlation between Age and Length of Experience and the Total Scores of the Psychiatric Nurse Job Stressor Scale (PNJSS) and Its Subscales $(n=137)$

\begin{tabular}{|l|r|r|r|r|}
\hline \multirow{2}{*}{ PNJSS Subscales } & \multicolumn{2}{c|}{ Age } & \multicolumn{2}{c|}{ Length of Experience } \\
\cline { 2 - 6 } & $\mathbf{r}$ & $\mathbf{p}$ & $\mathbf{r}$ & \multicolumn{1}{c|}{ P } \\
\hline Psychiatric nursing ability subscale & 0.124 & 0.099 & 0.147 & 0.088 \\
\hline Attitude of patients subscale & 0.062 & 0.469 & 0.024 & 0.780 \\
\hline Attitude toward nursing subscale & 0.092 & 0.287 & 0.045 & 0.604 \\
\hline Communication subscale & 0.086 & 0.318 & 0.215 & $0.011^{*}$ \\
\hline Total PNJSS & 0.035 & 0.683 & 0.120 & 0.163 \\
\hline
\end{tabular}

Table 6 presents the correlation between level of education and workplace with the psychiatric nurse job stressor scale total score and its four subscale scores. ANOVA test revealed only statistically significant correlation between level of education and the psychiatric nursing ability subscale $(p=0.001)$. While workplace found to be related to the communication subscale $(\mathrm{p}=0.001)$.

Table 6 Correlation between Level of Education and Workplace and the Total Scores of the Psychiatric Nurse Job Stressor Scale (PNJSS) and Its Subscales $(n=137)$

\begin{tabular}{|l|r|r|r|r|}
\hline \multirow{2}{*}{ PNJSS Subscales } & \multicolumn{2}{c|}{ Level of Education } & \multicolumn{2}{c|}{ Workplace } \\
\cline { 2 - 5 } & F & p & F & P \\
\hline Psychiatric nursing ability subscale & 8.010 & $0.001^{*}$ & 0.729 & 0.603 \\
\hline Attitude of patients subscale & 0.497 & 0.610 & 2.443 & 0.038 \\
\hline Attitude toward nursing subscale & 0.585 & 0.559 & 1.142 & 0.342 \\
\hline Communication subscale & 1.444 & 0.240 & 4.430 & $0.001^{*}$ \\
\hline Total PNJSS & 0.904 & 0.407 & 1.531 & 0.184 \\
\hline
\end{tabular}

Pearson R revealed strong statistical correlations between total PNJSS total score and all its four subscales $(\mathrm{p}=$ $0.000)$

Table 7 Correlations between Each Subscale Score and the Total PNJSS Score $(n=137)$

\begin{tabular}{|l|r|r|r|r|r|}
\hline & \multicolumn{1}{|c|}{$\begin{array}{c}\text { Psychiatric } \\
\text { nursing ability } \\
\text { subscale }\end{array}$} & $\begin{array}{c}\text { Attitude of } \\
\text { patients subscale }\end{array}$ & $\begin{array}{c}\text { Attitude toward } \\
\text { nursing subscale }\end{array}$ & $\begin{array}{c}\text { Communicat } \\
\text { ion subscale }\end{array}$ & $\begin{array}{c}\text { Total } \\
\text { PNJSS }\end{array}$ \\
\hline Psychiatric nursing ability subscale & 1 & 0.037 & 0.097 & 0.023 & $0.574^{* *}$ \\
\hline Attitude of patients subscale & 0.037 & 1 & $0.463^{* *}$ & $0.529^{* *}$ & $0.731^{* *}$ \\
\hline Attitude toward nursing subscale & 0.097 & $0.463^{* *}$ & $0.387^{* *}$ & $0.659^{* *}$ \\
\hline Communication subscale & 0.023 & $0.529^{* *}$ & $0.387^{* *}$ & 1 & $0.580^{* *}$ \\
\hline Total PNJSS & $0.574^{* *}$ & $0.731^{* *}$ & $0.659^{* *}$ & $0.580^{* *}$ & \\
\hline
\end{tabular}

$\mathrm{P}=000$

Table 7 presents that Pearson R revealed a strong statistical correlations between total PNJSS total score and all its four subscales $(\mathrm{p}=0.000)$

\section{Discussion}

This study was an endeavor to assess the extent of job stress among registered psychiatric nurses working in different psychiatric units of a major governmental psychiatric hospital located at the central region of the Kingdom of Saudi Arabia.

In the present study, various demographic variables were studied, among those age of the participants ranged between 20 to 55 years, while Hamaideh (2008) stated that majority of sample in their study was from middle age group. About 59.1\% participants of this study were male and $40.6 \%$ were female. This result was supported by the study of Hajjaj (2007) he reported that $70 \%$ of his study sample were male. Regarding years of experience as a psychiatric nurse ranged from one month to 22 years whereas the study done by Abdulla and Abbas, 2014 only had psychiatric nurses with five years and less work experience in psychiatric hospitals. Regarding education of psychiatric nurses in this study clarified that two thirds of the nurses had diploma degree in nursing, $32.1 \%$ held a bachelor degree in nursing and only three nurses had master's degree in nursing. This result can be compared with the research done by Zaki (2016) which spell out that majority of the participants were diploma nurses and no one had master's degree in nursing.

The level of job stress obvious in the present study describes that half of the participants had moderate level of job stress i.e. about $61 \%$ and only $4 \%$ of the psychiatric nurses had severe job stress. This when compared with the study done by Zaki (2016) summarizes that psychiatric nurses were suffering from job stress, but based on the responses of the psychiatric job stress scale, most of the nurses had a positive thought, they think that I can nurse and correspond as the case requires, I can explain the nursing that I am doing, I have psychiatric nursing ability, I have knowledge about the laws, the institutions and the policies necessary for nursing, I can express my opinion in front of others and feel that they can do integrated nursing this indicates the nurses ability to do their job with minimal job stress. In contrary the study done by Zaki (2016) showed that 
psychiatric nurses are suffering from job stress, most of the psychiatric nurses think that they did not have the psychiatric nursing ability, not have knowledge about the laws, the institutions and the policies necessary for nursing, can't be a nurse correspond as the case requires and can't express their opinion in front of others. The researcher identified that this could be due to psychiatric nurses' lack of preparation and proficiencies to deal with psychiatric patients which has enforced stress on the nurse's work and thus they lost the capability to do their job perfectly. Another study conducted by Ahanchian (2015) who studied nurse's burnout in psychiatric wards found that stressors are subsequently disturbing psychiatric nurse's ability to care for patients.

Concerning the attitude of patients the nurses feel that there are patients who have an unpleasant attitude toward them, patients are negative about them and that there are patients who are threatening and make them afraid this indicates that the psychiatric nurses feel that they are being pressured by patients demands, this finding might be due to lack of suitable work environment, also due to dealing with large number of patients who has at times unpredictable behaviors. This result is in congruent with study of Zaki (2016) exposes that the majority of psychiatric nurses are feeling that they are pressured by patients' demands, feeling that patients are negative about them, and feeling that there are patients threatening and making them afraid. Abushaikha (2009) assessed job satisfaction and burnout among Palestinian nurses in Gaza and revealed that more than one-third of nurses had reasonable levels of stress and minimal ability in dealing with a patient.

Regarding communication only $21 \%$ of nurses always think that it is difficult to communicate with the family of patients and $17 \%$ of nurses think that it is difficult to communicate with patients. Also it was evident in the present study that having Arabic language as the mother tongue was negatively associated with the psychiatric nursing ability subscale indicating low levels of psychiatric nurse job stress and was associated with communication subscale indicating less difficulty in communicating with patients and their families. This finding is different from the study done by Zaki (2016) which illustrate that more than half of psychiatric nurses are thinking that it is difficult to communicate with patients and the family of patients. Yoshizawa (2016) who studied the psychological impact of verbal abuse and violence by patients on nurses working in psychiatric departments in Japan, and conveyed that the mainstream of nurses answered that they had faced with verbal abuse that had lead them with fear to communicate with psychiatric patients.

Results of the present study revealed significant differences between male and female participants in relation to total PNJSS scores and the communication subscale. This can be compared with the study by Yada, Abe, Omori, Matsuo, Masaki, Ishida \& Katoh (2014) they quantitatively examined gender differences in psychiatric nurses' job stress. The results indicated that female nurses had significantly higher stress levels than males related to psychiatric nursing ability and attitude towards nursing. Krausz, Sagie and Bidermann (2000) compared male and female nurses working in psychiatric units showed that male nurses experienced a higher degree of emotional exhaustion. They viewed that male nurses had less coping ability as compared to female nurses.

In terms of nationality the current study found differences between Saudi and non-Saudi nurses working in psychiatric settings with regard to psychiatric nursing ability, attitude of patients, attitude toward nursing and communication while nationality made no difference in the total score of the PNJSS. Al-Turki, AlTurki, Al-Dardas, Al-Gazal, Al-Maghrabi \& Al-Enizi (2010) conducted a research in Saudi Arabia among nurses, they identified that the prevalence of burnout syndrome among multinational nurses was high. NonSaudi nurses were found to be more prone to emotional exhaustion than Saudi nurses. In a comparative study among psychiatric nurses about burnout Nolan, Dallender, Soares, Thompson, \& Arenetz (1999) found that English nurses met with more violence in their work than Swedish nurses. The English nurses also stated lower individual well-being, lower levels of self-esteem and higher workload.

The correlation between PNJSS subscales and age, length of experience as psychiatric nurse and workplace were studied. Statistically significant correlation was revealed between level of education and the psychiatric nursing ability. This can be compared with the research done by Zaki (2016) highlighted that there was no statistically significant relation between stress and psychiatric nurses' occupation and educational level. Furthermore Al Hosis, Mersal \& Keshk (2013) who studied the effect of job stress on the health of Saudi nurses working in the ministry of health hospitals in Qassim region in KSA found that nurses' work stress was not influenced by their educational level. Also significant relationship was found between work place and communication subscale. This goes in coincidence with the research done by Liu \& Wuerker (2005), Flannery, Farley, Rego \& Walker (2007), Hanrahan, Aiken, McClaine \& Hanlon (2010) these studies explained that psychiatric nurses constantly manage patients and families from all levels of people, and is essential to deal with manifold communications. Both hurts from work and verbal attacks from patients will increase psychiatric nurses' occupational burnout. Yada , Abe, Lu, Wakizaki, Omori, Matsuo, Ishida \& Katoh (2014) investigated the specificity and structures of job-related stress in psychiatric dementia nurses (PDNs) caring for elderly patients with serious behavioral and psychological symptoms of dementia job-related stress in PDNs revealed physical workload and work environment to be more significant stressors. The study by Zaki (2016) has explained that one of the factors influencing psychiatric nurse's ability to cope effectively with their work stress 
as uncooperative work place. Psychiatric nurses have an uncommon work setting Kane, (2012). As well association was found between length of experience and communication subscale, but when this result is compared with research done by Shih, Hou, Lin, Hsiao, Sun, Chou \& Yang (2016) they explained that nurses with 6-10 years' of experience have higher level of job stress than nurses with less than 5 years or more than 11 years' experience. Likewise the finding from $\mathrm{Su}$ (2008) recognized that middle aged nurses i.e with 6-10 years' experience are given full accountabilities at work, and many roles during this phase clarify why middle aged nurses experience job stress more often.

The result of the present study indicate that there is significant relationship between PNJSS total score and all its four items such as attitude toward nursing ability, attitude toward patients, attitude toward nursing and communication. This result can be related to the study conducted by Zaki (2016) the results specify that there was significant relation discovered in all aspects of psychiatric nurse's job stress.

The reasons for nurses' job stress may differ according to the altered situations of the psychiatric hospitals, organizational cultures and leadership styles or nurses' levels of professional ability, which grounds to job stress. The results of this current study can provide references for psychiatric nurses to assist them in understanding their views of stress, as well as deliver them with positive and strong coping strategies to inhibit job stress and encourage excellence in proficient psychiatric nursing care.

\section{Conclusions and Recommendations}

Based on the study results, it was concluded that most of the psychiatric nurses were experiencing moderate level of job stress concerning psychiatric nurse's ability, the attitude of patient, attitude to nursing and communication with patients and their families even though they had a positive thought. Moreover, there was significant relation found between length of experience as a psychiatric nurse and communication, relation between level of education and the psychiatric nursing ability and workplace found to be related to the communication subscale.

\subsection{Based on the findings of this study, the following recommendations are suggested:}

- Provide adequate feedback to nurses as regards to short term and long term expectations of their job perhaps through regular appraisal may enhance job performance.

- Organize instructional program for psychiatric nurses on how to cope positively with their job stressors.

- Reconsider the type of nursing care which male and female nurses can participate in order to reduce the job stress.

- Improve the consultation method by executing an employee wellbeing commission to ensure that they do not become hampered with stress from hostile attitudes of patients.

- Conduct orientation program for newly joined nurses to make them understand the gap between ideal and actual nursing.

- Provide psychiatric nurses training on therapeutic communication techniques.

- Periodic continuing educational programs should be organized to enrich the psychiatric nursing ability and develop a positive attitude toward psychiatric nursing and patients.

- Training courses on self -efficacy would help the psychiatric nurse to enhance their stress bearing capacity and also improve their job performance.

- Further research can be done in a larger group of psychiatric nurses in several psychiatric hospitals.

- Continuous workshop for understanding of the unique stressors and difficult situations that have an impact on psychiatric nurses.

\section{Funding}

This research received no specific grant from any funding agency in the public, commercial, or not-for-profit sectors.

\section{Conflict of Interests}

The authors declare that they have no conflict of interests with any organization regarding the materials discussed in this manuscript.

\section{Acknowledgment}

The authors would like to extend their thanks and appreciations to all participants who voluntarily participated in the study and shared their experience. 


\section{References}

[1]. Abdulla M., Abbas, I. (2014). Assessment of job stress for nurses in psychiatric hospitals at Baghdad city, Kufa Journal for Nursing Sciences. 5 (1), Pp. 1-6.

[2]. Abushaikha,L.(2009 ). Job satisfaction and burnout among Palestinian nurses. Eastern Mediterranean Health Journal. 15 (1), Pp. $190-196$.

[3]. Adriaenssens, J., De Gucht, Maes, S. (2013). Causes and consequences of occupational stress in emergency nurses, a longitudinal study. Journal of Nursing Management. 12 (3), Pp.222-240

[4]. Al-Ahmadi, H. (2009). Factors affecting performance of hospital nurses in Riyadh Region, Saudi Arabia. International Journal of Health Care. 22 (1), Pp. 40-54.

[5]. Al-Turki1, H., Al-Turki, R., Al-Dardas, H., Al-Gazal, M., Al-Maghrabi, G., Al-Enizi, N., Ghareeb, B. (2010). Burnout syndrome among multinational nurses working in Saudi Arabia. Ann Afr Med. 9, Pp. 226-9.

[6]. Ahanchian, R. (2015). Nurse's burnout in psychiatric wards of Fundamentals of Mental Health. 17(5), Pp. $260-64$.

[7]. Al Hosis,K., Mersal,F., and Keshk, L. (2013). Effect of job stress on health of saudi nurses working in ministry of health hospitals in qassim regionand. Life Science Journal. 1 (10), Pp. 1036.

[8]. Alsaraireh, F., Griffin, MT., Ziehm, SR., and Fitzpatrick, JJ. (2014) .Job satisfaction and turnover intention among Jordanian nurses in psychiatric units. International Journal of Mental Health Nursing. 23 (5), Pp 460-467.

[9]. Callaghan, P. (1991). Organization and stress among mental health nurses. Nursing Times journal.87 (34), Pp 50.

[10]. Cronin - Stubbs, D., Brophy, E. B. (1985). Burnout: can social support save the psychiatric nurses. Journal of Psychosocial Nursing in Mental Health Services. 23, Pp. 8-13.

[11]. Dawkins, E. J., Depp. F. L., Selzer, E .N. (1985). Stress and the psychiatric nurse. Journal of Psychosocial Nursing. 23 (11), Pp. 915 .

[12]. Duquette, A., Kerouac, S., Sandhu, B.K. (1994). Factors related to nursing burnout: A review of empirical knowledge. Journal Issues Mental Health Nursing. 15:357-358.

[13]. Farrel, G.A., Dares, G. (1999). Nursing staff satisfaction on a mental health unit. Australian and New Zealand of Mental Health Nursing. 8, 51-57.

[14]. Fioritti, A., Giaccotto, L., and Melega, V. (1997). Choking incidents among psychiatric patients: retrospective analysis of thirty-one cases from the West Bologna psychiatric wards. Canadian Journal of Psychiatry. 42(5), Pp. 515-520.

[15]. Flannery, R.B., Farley, E., Rego, S., \& Walker, A.P. (2007). Characteristics of staff victims of psychiatric patient assaults: 15-year analysis of the Assaulted Staff Action Program (ASAP).Psychiatric Quarterly, 78(1), 25-37.

[16]. Hajjaj, K.(2014) The impact of job stress on organizational commitment and job satisfaction among nursing staff in Shifa hospital of Gaza strip, Journal of Al-Azhar University - Gaza, Humanities Series. 3(2), Pp.35-112.

[17]. Hamaideh, S., Mrayyan, M., Mudallal, R., Faouri, I. and Khasawneh, N. (2010) Jordanian nurses' job stressors and social support, Journal compilation, International Council of Nurses. 55, Pp.41-48.

[18]. Handy, J. (1990). Occupational and contradiction in psychiatric nursing. Human Relations. 44, Pp. 39-53.

[19]. Hanrahan, N.P., Aiken, L.H., McClaine, L., \& Hanlon, A.L. (2010). Relationship between Psychiatric Nurse Work Environments and Nurse Burnout in Acute Care General Hospitals. Issues in Mental Health Nursing. 31(3), 198-207.

[20]. Kane, P. (2012). Stress causing psychiatric illness among nurses. j occup envnt med .13(1) available from www.ijoem.com

[21]. Kilfedder, Catherine, J., Kevin, P.G.,Tony, J. (2001).Burnout in psychiatric nursing. Journal of Advanced Nursing. 34 (3), Pp. 383396.

[22]. Krausz, M., Sagie, A., Bidermann. (2000). Actual and preferred work schedules and scheduling control as determinants of job related attitudes. Journal of vocational behavior. 56(1), Pp. 1-11.

[23]. Konstantinos, N., Christina, O. (2016). Factors influencing stress and job satisfaction of nurses working in psychiatric units: a research review. Health science Journal. Issue 1

[24]. (10), Pp. 33-37.

[25]. Liu, J., \&Wuerker, A. (2005). Biosocial bases of aggressive and violent behavior-implications for nursing studies. International Journal of Nursing Studies, 42(2), 229-241.

[26]. McVicar, A., (2003).Workplace stress in nursing: A literature review, integrativeliterature review and meta-analyses. Journal of Advance Nursing. 44(6), pp. 633-642.

[27]. Nolan, P., Dallender, J., Soares, J., Thompson, S., Arenetz, B. (1999).Violence in mental health care: the experience of mental health nurses and psychiatrists. J Adv Nurs. 30,934-941.

[28]. Olivia, F.A. (2011) .The Status of Mental Health Care in Ghana, West Africa and Signs of Progress in the Greater Accra Region. Berkeley Undergraduate Journal, 24(3).

[29]. Palmer, G., Boykin, A., Lythgoe, K., Bizzell, D., Daiss, D. (2005). Mental Health Professionals' Perceptions of Difficult Psychiatric Situations: A Brief Report on Development of the Psychiatric Situations Scale. The International Journal of Mental Health. 3 (1), Pp. 22-35.

[30]. Robinson, J.R., Clements, K., Land, C. (2003). Workplace stress among psychiatric nurses. Prevalence, distribution, correlates, \& predictors. Journal of Psychosocial Nursing and Mental Health. 41(4), 32-41.

[31]. Shih, E., Hou, W., Lin, P., Hsiao1, P., Sun, C., Chou, Y., Yang, T. (2016). Personal Characteristics, Workplace Stressors, and Occupational Burnout among Psychiatric Nurses in Southern Taiwan- A Cross-sectional Study. Nursing and Health. 4(2), 15-23,.

[32]. Su, M.H. (2008). Emotion Regluation in the Workplace of Nurses (Unpublished master's thesis).National Taipei University of Technology Institute of Commerce Automation and Management.

[33]. Stuhlmiller, C. (2003). Trauma, culture and meaning: central issues for mental health nursing. International Journal of Mental Health Nursing. 12 (1), 1-3.

[34]. Sullivan, J. P. (1993). Occupational stress in psychiatric nursing. Journal of Advanced Nursing.18, 591-601.

[35]. Torkelson, D.,Seed, M. (2011). Gender Differences in the Roles and Functions of Inpatient Psychiatric Nurses. Journal of Psychosocial Nursing and Mental Health Services. 49 (3), Pp. 34-41.

[36]. Wang W, Man Kong AW,Ying Chair S (2011). Relationship between job stress level and coping strategies used by Hong Kong nurses working in an acute surgical unit. Applied Nursing Research.Volume 24, (4), Pp. 238-243.

[37]. Wheeler, H.H., Riding, R. (1994). Occupational stress in general nurses and midwives. British Journal of Nursing. 3, Pp.527-534.

[38]. Yada H, Abe H, Omori H (2014). Differences in job stress experienced by female and male Japanese psychiatric nurses. International Journal of Mental Health Nursing. 23, (5), Pp. 468-476.

[39]. Yada, H., Abe, H., Funakoshi, Y., Omori, H., Matsuo,H., Ishida, Y., Katoh, T. (2011). Development of the Psychiatric Nurse Job Stressor Scale (PNJSS).Psychiatry and Clinical Neurosciences. 65, Pp. 567-575. 
[40]. Yada, H., Abe, H., Lu, X., Wakizaki, Y., Omori, H., Matsuo, H., Ishida, Y., Katoh, T. (2014). Job-related stress in psychiatric nurses in Japan caring for elderly patients with dementia. Environmental health and preventive medicine. 19 (6), Pp. 436-443.

[41]. Yoshizawa, K. (2016). Relationship between occupational stress and depression among psychiatric nurses in Japan. Archives of Environmental \& Occupational Health, 71, Pp. 10-15.

[42]. Zaki, R. (2016). Job Stress and Self- Efficacy among Psychiatric Nursing Working in Mental Health Hospitals at Cairo, Journal of Education and Practice.7 (20), Pp. $103-113$. 